\title{
PESQUISAS COLABORATIVAS INTERNACIONAIS NO CAMPO DA PSICOLOGIA DA MÚSICA: UM RELATO DE EXPERIÊNCIAS
}

Rosane Cardoso de Araújo ${ }^{1}$

Universidade Federal do Paraná rosanecardoso@ufpr.br 


\section{Resumo}

Ações de internacionalização têm sido cada vez mais incentivadas no âmbito dos Programas de Pós-Graduação no Brasil. O presente artigo traz como foco a apresentação de duas pesquisas internacionais, realizadas colaborativamente entre pesquisadores da Universidade de Bolonha (Itália) e da Universidade Federal do Paraná (Brasil). Os estudos apresentados foram conduzidos por meio de um estudo sobre representações sociais, com base na psicologia social, e de um estudo fundamentado na psicologia cognitiva/Psicologia, com foco na criatividade e na Teoria do Fluxo. Ambas as investigações trouxeram consequências relevantes para o programa de Pós-Graduação em Música da UFPR, gerando publicações colaborativas e desdobramentos em estudos posteriores que ampliaram as possibilidades investigativas para a linha de pesquisa cognição/ educação musical.

Palavras-chave: Internacionalização; Pesquisa em Música; Representações Sociais, MIROR Project.

\section{Abstract}

Internationalization actions have been increasingly encouraged under the Graduate Programs in Brazil. This article focuses on the presentation of two international researches, carried out collaboratively between researchers from the University of Bologna (Italy) and the Federal University of Paraná (Brazil). The studies presented were conducted through a study on Social Representations, based on Social Psychology, and a study based on Cognitive Psychology / Psychology, focusing on Creativity and Flow Theory. Both investigations brought relevant consequences for the UFPR Graduate Program in Music, generating collaborative publications and developments in subsequent studies that expanded the investigative possibilities for the Cognition / Music Education research line.

\footnotetext{
1 Professora associada da Universidade Federal do Paraná (Departamento de Artes). Atua nos cursos de Graduação em Música e Pós-Graduação em Música (Mestrado e Doutorado). É coordenadora do Programa de Pós-Graduação em Música da UFPR, vice-presidente da Associação Brasileira de Cognição e Artes Musicais e bolsista de produtividade em pesquisa pelo Conselho Nacional de Desenvolvimento Científico e Tecnológico (CNPq). Possui Doutorado em Música pela Universidade Federal do Rio Grande do Sul e Pós-Doutorado em Música pela Universidade de Bolonha (Itália).
} 
A internacionalização das instituições de ensino superior, segundo Miranda e Stallivieri (2017), tem sido cada vez mais foco de discussão no Brasil. Segundo os autores, a internacionalização é atualmente um dos propósitos que causa maior impacto na definição dos novos rumos para a educação superior no país. Por este motivo, a internacionalização da pós-graduação no Brasil tem passado por um momento de grande incentivo por parte das universidades e agências de fomento, fazendo com que projetos de pesquisa realizados com parcerias internacionais sejam cada vez mais incentivados e valorizados no meio acadêmico.

Para os autores Miranda e Stallivieri (2017, p.590) uma das primeiras iniciativas na busca pela internacionalização passa, justamente, pelo apoio às pesquisas colaborativas que propiciam ações conjuntas e recíprocas entre instituições envolvidas: "Historicamente, esse tema tem sido conduzido por algumas universidades brasileiras e o governo, no esforço de buscar projetos de colaboração em pesquisa e intercâmbio de estudantes com outros países [...]". Neste sentido, o presente artigo tem como escopo trazer o relato de duas experiências de pesquisas colaborativas internacionais realizadas no âmbito do Programa de Pós-Graduação em Música da Universidade Federal do Paraná, na linha de pesquisa cognição/educação musical. Estas duas experiências foram pioneiras na aproximação entre professores e alunos da Universidade Federal do Paraná e da Universidade de Bolonha, trazendo desdobramentos até o momento atual. Os estudos que seguem apresentados neste artigo foram as primeiras atividades de parceria que ocorreram entre as pesquisadoras Anna Rita Addessi e Rosane Cardoso de Araújo e foram vinculadas a projetos desenvolvidos no campo da psicologia da música.

O primeiro projeto, intitulado "A Comparative Research about Social Representations of music ou Il Sapere Musicale come Rapresentazione Sociale", 2 foi realizado em colaboração entre a Università di Bologna (Itália), Universidade Federal do Paraná (Brasil), Autonomy University of Barcelona (Espanha) e Levinsky College of Education (Israel). ${ }^{3}$ Neste artigo será apresentado especificamente o estudo comparativo desenvolvido entre Brasil e Itália (ADDESSI; ARAÚJO, 2011). Já o segundo projeto foi o MIROR Project (Musical Interaction Relying on Reflexion), que foi desenvolvido no âmbito do 7을 Programa de Pesquisa e Desenvolvimento da União Europeia (Commission's Seventh Framework Programme) sob a coordenação geral da professora pesquisadora Anna Rita Addessi, da Universidade de Bolonha, com a participação das seguintes instituições: Università degli Studi di Genova; Goeteborgs Universitet; National and Kapodistrian University of Athenas; The University of Exeter; Sony France (SONY FRANCE S.A.) e Compedia Software \& Hardware LTD (ADDESSI, 2011). No presente artigo será apresentado um dos primeiros estudos desenvolvidos em colaboração entre a Universidade de Bologna e a Universidade Federal do Paraná (ARAÚJO; ADDESSI, 2013, 2014).

\footnotetext{
2 Tradução: "Um estudo comparativo sobre representações sociais da música" - "Os saberes musicais como representação social".

3 Estudo realizado colaborativamente com as professoras/pesquisadoras Anna Rita Addessi (Itália), Rosane Cardoso de Araújo (Brasil), Assunta Valls (Espanha) e Claudia Gluschankof (Israel).
} 


\section{Pesquisa comparativa sobre representações sociais em música}

O primeiro projeto de pesquisa teve como foco a realização de um grande levantamento teórico-empírico sobre o conhecimento musical de professores, investigado à luz da Teoria das Representações Sociais de Serge Moscovici (2007). A pesquisa, aqui relatada, foi concentrada na investigação dos conceitos implícitos de música, musicalidade, criança musical e professor de música, de estudantes universitários de cursos de formação de professores, bem como nas correlações entre esses conhecimentos implícitos e as práticas de educação musical. A investigação foi realizada com estudantes de Pedagogia que frequentavam a disciplina de Didática da Música (Educazione al Sonoro), na Itália, e com alunos de Licenciatura em Música, no Brasil ${ }^{4}$.

O estudo foi realizado com base na hipótese de que os conceitos de música e musicalidade podem estar relacionados a uma representação, isto é baseado numa construção psicológica e social. Para Moscovici (2007), as representações sociais podem ser definidas como um conjunto de afirmações, explicações e conceitos, que possui origem na vida cotidiana e sobre os qual o sujeito constrói suas inter-relações. São processos simbólicos que guiam as decisões e os comportamentos individuais na construção da realidade (ADDESSI; ARAÚJO, 2011). Assim, futuros professores de música, por meio de seus conhecimentos implícitos e suas concepções, poderiam ter diferentes impressões sobre o que é musicalidade e o que é musica, a ponto de afetar sua identidade profissional, bem como sua forma de ensinar e de aprender. O foco deste estudo, portanto, foi o levantamento de diferentes conhecimentos implícitos, de professores de música que influenciam suas próprias práticas didáticas, e não somente uma investigação dos diferentes significados que as palavras musicalidade e música podem ter (ADDESSI; ARAÚJO, 2011).

Os conhecimentos construídos pelos alunos de Licenciatura em Música sobre musicalidade, música, musicalidade infantil e as características do professor de música trazem a função primordial das representações sociais, que, segundo Ramos (2019, p.55), é "ser veículo de coesão social [...] na medida em que elas produzem familiaridade através do estabelecimento do senso comum, entendido aqui em sua literalidade de sensitividade compartilhada". Assim, as representações sociais envolvem combinação de ideias complexa, estereótipos, conceitos que nascem e se desenvolvem ao longo das dinâmicas psicossociais vivenciadas. No campo da psicologia social, observa-se um particular interesse de pesquisadores no estudo sobre representações sociais no ensino da música, como nos trabalhos de Ramos (2019), Rauski e Rosso (2017), Rauski (2015), Soares (2015), dentre outros, bem como sobre os conhecimentos implícitos dos professores, como é possível observar nos trabalhos de Hargreaves et al. (2007), Marshall e Hargreaves (2007), Araújo, Santos e Hentschke (2010), Forester (2017) etc.

Sobre o conceito de musicalidade, vários autores têm discorrido no sentido de compreender o termo, no entanto não existe um consenso. Para Hallam (2016), musicalidade é um termo associado ao "ser musical", definido como gostar ou ter habilidade

40 artigo completo sobre esta pesquisa foi publicado em Addessi e Araújo (2011). 
com a música. A autora também chama atenção para outros significados do termo recorrentes na literatura musical, como "habilidade musical", "atitude musical", "potencial musical" e "talento". Para Maffioletti (2001), o conceito de musicalidade traz repercussões sobre a forma como os professores de música concebem suas práticas de ensino.

Para esta pesquisa, portanto, o objetivo foi a verificação das concepções de licenciandos em Música sobre o que é música, musicalidade, sobre as características da musicalidade infantil, bem como a identificação das características (habilidades necessárias) do professor de música e do significado da educação musical em diferentes fases escolares. A pesquisa foi desenvolvida em duas grandes etapas: uma etapa inicial, de aplicação de um estudo-piloto realizado na Itália e apresentada por Addessi, Carugati, Selleri (2007) e Addessi e Carugati (2010), e uma etapa final, de aplicação do questionário em outros países, a saber: Brasil, Espanha e Israel (ADDESSI et al., 2010). Os resultados dos polos Brasil e Itália, acerca das concepções de música, musicalidade e características da musicalidade infantil, seguem apresentados neste texto.

O estudo de levantamento teve como instrumento de coleta de dados um questionário aberto apresentado a estudantes universitários que se encontravam no final de um curso de Licenciatura em Música (no Brasil) e a alunos que se encontravam no início e no final de um curso de formação de professores e que frequentavam uma disciplina de didática da música (Itália). No questionário, os participantes foram solicitados a completar algumas frases, como: "Música é...", "A musicalidade é...", além de perguntas sobre "musicalidade infantil", o conceito de educação musical e o perfil profissional dos professores de música. As questões apresentadas no questionário foram divididas em dados de caracterização dos respondentes (idade, sexo, formação musical, experiência em docência); concepções sobre música, musicalidade, características da musicalidade infantil em diferentes fases etárias; graus de musicalidade; e características do professor e significado da educação musical. Neste texto são trazidas as sínteses dos resultados obtidos para o conceito de música, musicalidade e as características da musicalidade infantil.

No Brasil foram coletados 50 questionários com alunos que se encontravam nos últimos anos do curso de Licenciatura em Música (terceiro e quarto anos). A pesquisa foi realizada no Departamento de Artes da Universidade Federal do Paraná, na cidade de Curitiba. Os participantes, ao responderem sobre o que é música, indicaram as categorias mais citadas no estudo-piloto realizado na Itália, isto é, citaram a música como "estrutura", a música como "comunicação e expressão" e a música como "emoção". Estes resultados, portanto, coincidiram com o resultado alcançado com os estudantes italianos. Além destas três categorias, também foram citados outros termos para definição de música, como cultura, estilo, experiência estética, intencionalidade, dentre outros. Também foram indicados outros termos na categoria "outros", na qual a definição do conceito de música foi aproximado à ideia de uma produção essencialmente humana.

Sobre a perspectiva do conceito da "criança musical", a maioria dos participantes brasileiros acreditava que existiam crianças com mais musicalidade que outras (70\%). Os que negaram esta constatação (30\%) justificaram acreditar que não existiam crianças mais musicais, mas que crianças se tornam mais ou menos musicais de acordo com o 
contexto em que se desenvolvem. Sobre as características da musicalidade infantil, isto é, os aspectos que destacam as crianças com maior musicalidade, os estudantes brasileiros indicaram: 1) presença de habilidades musicais específicas; 2) atração pela música; 3) forma de executar as atividades musicais. Também foram citadas outras categorias, com menos ênfase, como a alegria, a criatividade da criança ao fazer música. Na categoria "outros" foi incluída a questão da expressividade infantil.

Na Itália participaram do estudo 447 alunos em início de curso e 352 alunos em final do curso de Ciências da Educação, que cursavam uma disciplina de didática da música (Educazione al Sonoro) na Universidade de Bolonha (Bolonha/ltália). Para o conceito de música (música é...), foram indicadas 17 categorias de respostas, dentre as quais os conceitos mais citados foram: 1) Estrutura, 2) Comunicação, 3) Emoção.

Sobre a "musicalidade infantil", as respostas dos participantes italianos foram diversas, mas a maioria dos participantes, assim como os participantes brasileiros, afirmou que "existem crianças mais musicais". Também foram destacadas algumas categorias de respostas para identificar características da musicalidade infantil. Dentre as categorias mais indicadas pelos futuros professores italianos, foi possível observar que eles percebem a musicalidade das crianças por meio da presença de habilidades musicais específicas (como facilidade rítmica, afinação, aspectos motores, dentre outras); pela forma como as crianças se sentem atraídas pelas atividades musicais; pela forma como executam as atividades musicais; e também como percebem a música, ou seja, como escutam e apreciam a música.

Ao reconhecer os conhecimentos implícitos dos estudantes universitários, interpretados por meio da Teoria das Representações Sociais, foi possível compreender as concepções dos participantes nos dois polos (Brasil e Itália) sobre música e musicalidade e compará-las. De acordo com Moscovici (2007), frequentemente pode-se considerar os conhecimentos originários da representação social como contrários ao pensamento científico. Neste sentido, a busca por estas concepções e a compreensão dos pensamentos que frequentemente guiam as ações dos estudantes, futuros professores de música, pode ser de grande valia para os educadores que atuam no ensino superior, no sentido de auxiliar os estudantes a reconhecerem, avaliarem e revalidarem conceitos, preconceitos e ideias acerca da educação musical.

Embora a coleta de dados deste estudo seja relativa a grupos de estudantes de contextos distintos, os resultados foram muito semelhantes. Os dados obtidos junto aos estudantes brasileiros e italianos sugerem que as representações sociais sobre música e musicalidade infantil estão associadas às experiências individuais e a crenças partilhadas. De acordo com Moscovici (2002), as representações sociais apresentam crenças nucleares (crenças básicas) sobre as quais os sujeitos integram suas experiências particulares. Estas experiências, segundo o autor, quando partilhadas no espaço da representação, podem produzir transformações. Campos e Rouquette (2003), ao abordar as diferentes dimensões das representações sociais, por sua vez, destacam que estas são permeadas por elementos cognitivos e afetivos. Neste sentido, as opiniões sobre música e musicalidade dos estudantes puderam ser compreendidas como "impressões permeadas de elementos cognitivos e afetivos, construídas em momentos distintos de 
suas vidas, seja no contexto familiar, acadêmico, enfim, em diferentes circunstâncias" (ADDESSI; ARAÚJO, 2011, p.363). Em síntese, as principais conclusões obtidas com o presente estudo foram:

1. A maioria dos estudantes - futuros professores -, tanto os italianos quanto os brasileiros, acreditam que existem crianças mais musicais que outras e para comprovar esta afirmação conseguem identificar elementos que foram categorizados nesta pesquisa.

2. Ambos os grupos - de estudantes italianos e brasileiros - percebem a musicalidade das crianças por meio da observação de habilidades específicas no fazer musical.

3. A forma como as crianças se sentem atraídas pelas atividades musicais é um elemento significativo para os futuros professores observarem elementos de musicalidade infantil.

4. Também o modo como as crianças executam as atividades musicais, bem como elas percebem a música, são dados relevados pelos estudantes como elementos que indicam musicalidade.

5. Já o conceito de música, ou seja, a definição de o que é a música, trouxe especialmente três categorias específicas nos dados dos alunos italianos e brasileiros, isto é, a música foi considerada como uma forma 1) de comunicação, 2) de estrutura e 3) de emoção, dentre outras categorias citadas. (ADDESSI; ARAÚJO, 2011, p.364).

\section{MIROR Project: um estudo sobre criatividade em contexto interativo-reflexivo}

O MIROR Project (Musical Interaction Relying on Reflexion) ${ }^{5}$ teve como escopo o desenvolvimento de uma plataforma tecnológica que contém três sistemas tecnológicos interativos/reflexivos: MIROR Impro (MIROR improvisação), MIROR Compo (MIROR composição) e MIROR Body-gesture (MIROR gesto-corporal), que permitem à criança participar de atividades de composição, improvisação e de criatividade motora, por meio da utilização do movimento corporal. Segundo Addessi e Bonfiglioli (2017), os Sistemas Musicais Interativos/Reflexivos (SMIRs) foram concebidos pela SONY Computer Science Laboratory em Paris e caracterizam-se pela habilidade de responder ao sujeito durante a interação. Os SMIRs são percebidos pelo executante como uma espécie de "espelho" de suas ações e, segundo Addessi e Bonfigliolo (2017), seguem o paradigma da interação reflexiva, podendo ser aplicado ao campo da criatividade musical. Neste sentido, segue a apresentação de um estudo realizado em parceria (Brasil-Itália) e divulgado no Brasil por Araújo e Addessi (2014). ${ }^{6}$

O presente estudo foi parte dos experimentos psicológicos aplicados à interface do MIROR Impro. O MIROR Impro prevê a interação reflexiva por meio da improvisação musical. Enquanto a criança toca o teclado acoplado à Plataforma MIROR, ele ouve a resposta de sua improvisação, isto é, o teclado "responde" a sua execução, com um estilo semelhante ao dela. Esta interação cria uma espécie de "diálogo" musical compartilhado.

5 Musical Interaction Relying on Reflexion: Interação Musical Baseada na Reflexão.

60 estudo completo foi divulgado em Araújo e Addessi (2014). 
O estudo foi conduzido como estudo de caso, realizado a partir da análise de um vídeo sobre a interação de duas crianças com o sistema MIROR Impro. O objetivo geral foi investigar os processos criativos das crianças observando a construção das ideias musicais por meio da interação sem e com o sistema MIROR Impro, confrontando elementos que podem gerar a experiência de fluxo. Foram utilizadas as categorias de Torrance e Ball (1990) sobre criatividade e os estudos sobre "Teoria do Fluxo" (Flow theory) de Csikszentmihalyi (2003, 1999, 1996, 1992, 1990). De acordo com este autor, o fluxo (ou estado de fluxo) é gerado por componentes afetivos da motivação, incluindo emoção e concentração, que orientam a execução de uma atividade com grande envolvimento. O indivíduo, quando se encontra no "fluxo", encontra-se imerso, concertado e totalmente focado na atividade, a ponto de perder até mesmo a noção de tempo.

No estudo de caso, foram considerados os processos criativos a partir da interação das crianças individualmente e coletivamente durante as atividades de improvisação musical com o teclado sem e com o sistema MIROR Impro. Para as análises, foram consideradas cinco indicadores (do total de onze) de Torrance e Ball (1990) de avaliação da criatividade: ${ }^{7}$ presença da emoção; fantasia, movimento, combinação de ideias e perspectiva interna.

Os dados para realização deste estudo de caso foram coletados em uma escola de ensino fundamental da cidade de Casalecchio (Itália). Foram analisados vídeos de uma sessão de interação musical realizada com duas meninas de oito anos, dividida em quatro partes, ou quatro tasks (tarefas): (1) Task 1: a criança sozinha, tocando num teclado simples; (2) Task 2: a criança sozinha, tocando com MIROR Impro; (3) Task 3: a criança com a colega, tocando no teclado simples; (4) Task 4: a criança com a colega, tocando com o MIROR Impro.

A "emoção" foi o primeiro indicador de criatividade analisado com base em Torrance e Ball (1990). A emoção também é destacada por Csikszentmihalyi (1999) como um elemento significativo para a motivação e o envolvimento prazeroso da criança na atividade. No estudo de caso, foi possível identificar diversos momentos em que a emoção (euforia, alegria na execução da atividade) estava presente durante a prática da improvisação, especialmente quando as crianças estavam interagindo com o sistema reflexivo MIROR Impro. Tal entusiasmo, observado com as duas meninas na interação com o sistema reflexivo, também foi apontado em estudos anteriores por Addessi e Pachet $(2005,2007)$. O resultado, portanto, reforçou estudos precedentes.

O segundo indicativo de criatividade analisado foi a "fantasia", que foi alcançada pelas crianças durante todas as sessões de interação, tanto com o teclado simples quanto com o sistema reflexivo MIROR Impro:

Um exemplo desta constatação foi verificado após um período mais longo de exploração coletiva, onde as crianças participantes, depois de várias experiências de criação musical, encontraram um modelo sonoro que identificaram como uma característica de "filme de terror". Ambas as meninas compartilharam desta

7 Estes autores apontam 11 indicadores de criatividade: a presença da emoção, fantasia, movimento, combinações de ideias, resistência ao fechamento, perspectiva incomum, perspectiva interna, humor, riqueza de imagens, colorido de imagens e títulos expressivos. 
ideia e seguiram por um determinado período buscando combinações diversas para a construção da ideia do "filme de terror". Na sequência da atividade de improvisação, elas por fim encontram também um padrão de "filme para crianças", mudando, portanto a imagem (fantasia). (ARAÚJO; ADDESSI, 2014, p.86).

O terceiro indicador analisado foi o "movimento". Neste estudo, o movimento foi considerado a partir da abordagem do gesto criativo. Para Godoy e Leman (2012), as experiências musicais frequentemente estão conectadas com experiências de movimento. Assim, os autores propõem a expressão musical gestures para identificar a combinação entre som e movimento. Para os autores, o estudo do gesto musical pode remodelar nossos conceitos de música e som.

Assim, o elemento criativo "movimento" foi visualizado no estudo de caso a partir da análise do gesto musical das crianças. O gesto foi avaliado por meio da intencionalidade, utilizado pelas crianças "para criar efeitos expressivos e musicais e controlar as sonoridades particulares produzidas" (ARAÚJO; ADDESSI, 2014, p.84). Os gestos foram analisados tanto na execução individual (tasks 1 e 2) como na execução coletiva (tasks 3 e 4) e foram particularmente observados na interação com o sistema MIROR Impro.

O indicador de criatividade "combinação de ideias" foi observado igualmente nas atividades de improvisação desenvolvidas com o teclado simples e com o sistema MIROR Impro. Durante o ciclo de interação, a exploração musical das crianças seguiu um padrão anteriormente estudado por Addessi e Pachet (2005) sobre o ciclo de vida da interação musical com sistemas interativos/reflexivos. O desenvolvimento das atividades de improvisação trouxe elementos criativos gerados por combinações realizadas seja na prática individual, conforme apontam Torrance e Ball na categoria "perspectivas internas", seja na prática coletiva. Foram observados os seguintes elementos: a) Elementos iniciais de exploração livre (em cada etapa), como escalas, glissandos e clusters; e b) Elementos combinados, como busca de padrões, exploração harmônica, criação de frases pentatônicas, criação de frases pentatônicas associadas a elementos rítmicos e harmônicos e criação de ostinatos.

Por fim, uma análise quantitativa do estudo de caso foi realizada para mensurar a duração média de cada indicador de criatividade. A Tabela 1 apresenta o resultado dos dados descritivos desta análise:

\begin{tabular}{lllll} 
& $\begin{array}{l}\text { TASK 1 (tarefa 1) - A } \\
\text { criança toca sozinha } \\
\left(2^{\prime} 20^{\prime \prime}\right)\end{array}$ & $\begin{array}{l}\text { TASK 2 (tarefa 2) - A } \\
\text { criança toca sozinha } \\
\text { com o MIROR Impro } \\
\left(2^{\prime} 34^{\prime \prime}\right)\end{array}$ & $\begin{array}{l}\text { TASK 3 (tarefa 3) - A } \\
\text { criança toca com um } \\
\text { companheiro }\left(23^{\prime \prime} 23^{\prime \prime}\right)\end{array}$ & $\begin{array}{l}\text { TASK } 4 \text { (tarefa 4) - A } \\
\text { criança toca com um } \\
\text { companheiro e com o } \\
\text { MIROR Impro }\left(6^{\prime} 21^{\prime \prime}\right)\end{array}$ \\
\hline EMOÇÃO & $0^{\prime} 06^{\prime \prime}=4 \%$ & $1^{\prime} 17^{\prime \prime}=\mathbf{5 0} \%$ & $1^{\prime} 06^{\prime \prime}=5 \%$ & $2^{\prime} 36^{\prime \prime}=41 \%$ \\
\hline FANTASIA & -------- & $0^{\prime} 24^{\prime \prime}=\mathbf{2} \%$ & ---- \\
\hline MOVIMENTO & $0^{\prime} 17^{\prime \prime}=12 \%$ & ----- & $1^{\prime} 27^{\prime \prime}=6 \%$ & $1^{\prime} 34^{\prime \prime}=\mathbf{2 5} \%$ \\
\hline $\begin{array}{l}\text { COMBINAÇÃO DE } \\
\text { IDEIAS }\end{array}$ & $0^{\prime} 29^{\prime \prime}=21 \%$ & $1^{\prime} 03^{\prime \prime}=\mathbf{4 0} \%$ & $5^{\prime} 54^{\prime \prime}=21 \%$ & $2^{\prime} 32^{\prime \prime}=\mathbf{4 0} \%$ \\
\hline
\end{tabular}

Tabela 1: Análise quantitativa dos elementos de criatividade.

Fonte: Araújo e Addessi (2014, p.86). 
Os dados quantitativos proporcionam uma base para análise dos dados qualitativos, revelando que os elementos de criatividade "emoção" e "combinação de ideias", aqui descritos, foram observados de forma mais enfática quando as crianças tocavam interagindo com o sistema MIROR Impro.

Por fim, também foram verificadas algumas relações possíveis entre o estado de fluxo (CSIKSZENTMIHALYI, 1999) e a criatividade, encontradas neste estudo a partir da observação do processo de improvisação das crianças com e sem o sistema MIROR Impro, como:

a) A estruturação da prática, ou seja, a construção de padrões musicais baseados nas categorias de Torrance e Ball (1984) "combinações de ideias" e na "perspectiva interna", demonstra um processo que Csikszentmihalyi (1999), na teoria do fluxo, associa ao estabelecimento de metas claras.

b) A emoção - estado de alegria, entusiasmo -, definida por Torrance e Ball (1984) como um componente do processo criativo, também é descrita por Csikszentmihalyi (1999) como um elemento constituinte da experiência do fluxo.

c) Por fim, as categorias de Torrance e Ball (1984) analisadas neste texto como "movimento" e "fantasia" podem ser associadas a um processo mental que envolve especialmente uma situação de grande concentração. Um processo onde a energia psíquica do indivíduo está focalizada totalmente na atividade a ponto de manter uma intensa concentração, que, de acordo com Csikszentmihalyi, é um elemento-chave para gerar o estado do fluxo. (ARAÚJO; ADDESSI, 2014, p.86-87).

As análises qualitativa e quantitativa dos dados, portanto, indicaram que os comportamentos criativos eram mais evidentes quando as crianças executavam o sistema MIROR Impro, corroborando a hipótese de que a interação reflexiva possibilita a criatividade musical. Também foi explorada a hipótese de que os indicadores de criatividade analisados poderiam estar relacionados com os indicadores de fluxo descritos por Csikszentmihalyi (1999). Esta relação explorada por meio da pesquisa reforçou a ideia de que as crianças envolvidas em ambientes interativos/reflexivos possuem uma oportunidade particular para a realização de uma prática musical criativa. Posteriormente, muitos outros estudos foram realizados colaborativamente com pesquisadores da Itália e do Brasil com base nas análises psicológicas sobre a interação reflexiva a partir do sistema MIROR. O tipo particular de tecnologia baseada sob o paradigma de interação reflexiva, avaliada por meio das pesquisas realizadas, se revelou um modelo eficaz no âmbito da aprendizagem musical e seguiu sendo sistematicamente investigado. Os estudos realizados têm trazido resultados que demonstram que os modelos interativos/ reflexivos "são um modelo viável para o desenvolvimento musical da criança, especialmente pelo caráter lúdico e criativo que esse processo de interação permite" (ARAÚJO; ADDESSI, 2014, p.78). 


\section{Contribuições dos dois estudos apresentados para ações de internacionalização na UFPR}

Os dois estudos apresentados, resultantes dos projetos internacionais, tiveram como foco a área da Psicologia/psicologia da música. O primeiro estudo, sobre representações sociais, entra no campo dos estudos sobre psicologia social, área que ainda demanda muitas investigações no contexto nacional. O referido estudo, por sua vez, propiciou a continuidade das investigações na área da psicologia social em outros estudos desenvolvidos no Programa de Pós-Graduação em Música posteriormente, a saber: Ramos (2019), Araújo et al. (2018), Opiechon e Araújo (2017), Araújo (2017, 2015a). Estes estudos posteriores, por sua vez, ampliaram as pesquisas sobre representações sociais em contextos distintos, como no campo do ensino instrumental, das práticas em contexto de música popular, bem como reforçaram os estudos sobre o pensamento do professor de música.

Da mesma forma, estudos sobre o MIROR Project tiveram muitos desdobramentos. Estudos posteriores, envolvendo a Universidade de Bolonha e a Universidade Federal do Paraná, foram aprofundados, gerando muitas publicações, como os estudos de Araújo, Pscheidt e Addessi (2019), Addessi, Pscheidt e Araújo (2019 e 2017), Figueiredo, Lüders e Santos (2019), Pscheidt e Araújo (2017), Araújo (2015b), Araújo e Addessi (2013), Addessi e Araújo (2013). Nestes estudos foram incluídos novos contextos de investigação e novos objetos na interface com o sistema MIROR, como a didática musical em sistema interativo/reflexivo, práticas musicais envolvendo alunos e professores, práticas de ensino no contexto da educação especial, dentre outras abordagens.

\section{Considerações finais}

Os relatos de pesquisas apresentados, resultantes de projetos internacionais colaborativos entre Brasil e Itália, foram considerados estudos pioneiros para os processos de internacionalização das pesquisas na área da cognição/educação musical no contexto do Programa de Pós-Graduação em Música da UFPR. A execução destes estudos propiciou a aproximação de pesquisadores da Universidade de Bolonha e da Universidade Federal do Paraná, trazendo, como consequência, o posterior envolvimento de outros estudantes e professores nas ações colaborativas internacionais. Neste sentido, a professora Anna Rita Addessi, da Universidade de Bolonha, passou a ser professora visitante no Programa de Pós-Graduação em Música da UFPR em 2012, atuando cada vez mais como professora, pesquisadora e orientadora e abrindo espaço para que atualmente se tenha, como fruto desta colaboração, o primeiro processo de cotutela entre UFPR e Unibo, processo este que permite a dupla titulação no curso de doutorado, isto é, uma titulação que é recebida no Brasil, pela Universidade Federal do Paraná, e na Itália, pela Universidade de Bolonha. No momento, encontra-se em formação para obtenção do primeiro título de cotutela uma estudante de Doutorado em Música da UFPR.

Os processos de internacionalização, portanto, são notoriamente um caminho de desenvolvimento para as pesquisas da área da Música no Brasil e propiciam ricas expe- 
riências de crescimento acadêmico para as partes envolvidas. No campo da educação musical, por exemplo, tais estudos permitem adentrar tanto no campo educação musical comparada quanto em estudos mais universais, voltados, por exemplo, para os campos da Psicologia ou da cognição. Espera-se, portanto, com o relato dos estudos acima descritos, motivar cada vez mais professores e estudantes a investirem nas ações de internacionalização por meio de novas e desafiadoras pesquisas, desenvolvidas em colaboração com pesquisadores estrangeiros, envolvendo de forma integrada professores e estudantes de Música de todos os níveis de ensino.

\section{REFERÊNCIAS}

ADDESSI, A. R.; ARAÚJO, R. C. Um estudo sobre representações sociais de alunos de graduação sobre os conceitos de. In: SIMPÓSIO INTERNACIONAL DE COGNIÇÃO E ARTES MUSICAIS, 7., 2011, Brasília. Anais [...]. Brasília: Fundação Darcy Ribeiro, 2011. V. 1. p. 355-365.

ADDESSI, A. R.; ARAÚJO, R. C. Designing the Miror-Body Gesture Framework for Music and Dance Creativity. In: SIMPÓSIO DE COGNIÇÃO E ARTES MUSICAIS, 9., 2013, Belém. Anais [...]. Belém: UFPA, 2013. V. 1. p. 74-94.

ADDESSI A. R.; ARAÚJO, R. C.; VALLS, A.; GLUSCHANKOF C. A comparative research about social representations of music held by university students. In: INTERNATIONAL CONFERENCE ON MUSIC PERCEPTION AND COGNITION PROCEEDINGS, 11., 2010, Seattle. Proceedings [...]. Seatle: University of Washington, 2010. p. 28-35.

ADDESSI, A. R.; BONFIGLIOLI, L. Interação Reflexiva como paradigma transversal para a criatividade, educação musical e musicoterapia. Orfeu, v. 2, n. 2, p. 175-199, 2017.

ADDESSI, A. R.; CARUGATI, F.; SELLERI, P. Music teachers' knowledge and social representations of music. In: SIMPÓSIO DE COGNIÇÃO E ARTES MUSICAIS INTERNACIONAL, 3., 2007, Salvador. Anais [...]. Salvador: UFBA, 2007, p. 138-151.

ADDESSI, A. R.; CARUGATI, F. Social representations of "musical child" held by university students: an empirical investigation on implicit music knowledge in Higher Teacher Education. Music Education Research, v. 3, n. 12, 2010.

ADDESSI, A. R.; PACHET, F. Experiments with a musical machine: musical style replication in 3/5 year old children. British Journal of Music Education, v. 22, p. 21-46, 2005.

ADDESSI, A. R.; PACHET, F. Sistemas musicais interativos-reflexivos para educação musical. Cognição e Artes Musicais, Curitiba: DeArtes, v. 2, n. 1, p. 62-72, 2007. 
ADDESSI, A. R.; PSCHEIDT, J.; ARAÚJO, R. C. Stili e identità musicali nell'infanzia in ambienti riflessivi. Rivista Infanzia (Firenze), v. 3, p. 218-224, 2017.

ADDESSI, A. R.; PSCHEIDT, J.; ARAÚJO, R. C. Arts and childhood: children's musical styles in a "reflexive" environment. DEDiCA: Revista de Educação e Humanidades (Dreh-España), v. 16, p. 109-127, 2019.

ARAÚJO, R. C. Representações sociais na prática de ensino de professores de instrumento. In: CONGRESSO DA ANPPOM, 25., 2015, Vitória. Anais [...]. Vitória: ANPPOM, 2015a. V. 1. p. 1-6.

ARAÚJO, R. C. Improvvisazioni con la piattaforma MIROR. In: ADDESSI, Anna Rita (org.). La creatività musicale e motoria dei bambini in ambienti riflessivi. 1. ed. Bolonha/ Itália: Bononia University Press, 2015b. V. 1, p. 79-86.

ARAÚJO, R. C.; ADDESSI, A. R. Children's musical improvisation in an interactive/ reflexive musical context: a study. In: SIMPÓSIO DE COGNIÇÃO E ARTES MUSICAIS, 9., 2013, Belém. Anais [...]. Belém: UFPA, 2013. V. 1, p. 95-105.

ARAÚJO, R. C.; ADDESSI, A. R. Um estudo sobre a improvisação musical de crianças num contexto musical interativo/reflexivo. Música em Contexto (UnB), v. 1/2014, p. 7691, 2014.

ARAÚJO, R. C.; OPIECHON, S. S.; ARAÚJO, C. B.; ALONSO, M. V. Perspectivas de estudantes/professores de música sobre o conceito de criatividade musical e características do comportamento musical criativo. Percepta: Revista de Cognição Musical, v. 5, p. 39-50, 2018.

ARAÚJO, R. C.; PSCHEIDT, J.; ADDESSI, A. R. Interação reflexiva e a criatividade musical empática. In: ARAÚJO, Rosane Cardoso de (org.). Educação musical: criatividade e motivação. 1. ed.Curitiba: Appris, 2019. V. 1, p. 161-182.

ARAÚJO, R. C.; SANTOS, E. A.; HENTSCHKE, L. The development of piano teachers knowledge: three case studies from Brazil. Visions of Research in Music Education, $\mathrm{n}$. 13, p. 1-19, 2010.

CAMPOS, P. H. F.; ROUQUETTE, M. L. Abordagem estrutural e componente afetivo das representações sociais. Psicologia, Reflexão e Crítica, Porto Alegre, v. 16, n. 3, p. 435445, 2003.

CSIKSZENTMIHALYI, Mihaly. Flow: the psychology of optimal experience. New York: Harper \& Row, 1990. 
CSIKSZENTMIHALYI, Mihaly. A psicologia da felicidade. São Paulo: Saraiva, 1992.

CSIKSZENTMIHALYI, Mihaly. Creativity: flow and the psychology of discovery and invention. New York: Harper Collins, 1996.

CSIKSZENTMIHALYI, Mihaly. A descoberta do fluxo. Psicologia do envolvimento com a vida cotidiana. Rio de Janeiro: Rocco, 1999.

CSIKSZENTMIHALYI, Mihaly. Good business: flow, leadership and making of meaning. New York: Viking, 2003.

FIGUEIREDO, C. F.; LUDERS, V.; SANTOS, A. P. A interação musical do estudante com transtorno do espectro do autismo em um ambiente digital. In: TECNOLOGIA, MÚSICA E DIVERSIDADES, Recife. Anais [...]. Recife: NICS Reports Núcleo Interdisciplinar de comunicação sonora, 2019. V. 1. p. 29-38.

FORESTER, S. Music teacher knowledge: an examination of the intersections between instrumental music teaching and conducting. Journal of Research in Music Education, v. 65, n. 4 , p. $461-482,2017$.

GODOY, Rolf; LEMAN, Marc. Musical gestures: sound, movement and meaning. London: Routledge, 2012.

HALLAM, S. Musicality. In: MCPHERSON, G. (ed.). The child as musician: a handbook of musical development. 2. ed. Oxford: Oxford University Press, 2016. p. 67-80.

HARGREAVES, D. J.; PURVES, R. M.; WELCH, G.; MARSHALL, N. A. Developing identities and attitudes in musicians and music teachers. British Journal of Educational Psychology, v. 3, n. 77, p. 665- 682, 2007.

MARSHALL, N.; HARGREAVES, D. J. Crossing the humpback bridge: Primary-secondary school transition in music education. Music Education Research, v. 9, p. 65-80, 2007.

MIRANDA, A. A.; STALLIVIERI, L. Para uma política pública de internacionalização para o ensino superior no Brasil. Revista Avaliação, v. 22, n. 3, p. 589-613, nov. 2017

MOSCOVICl, Serge. Representações sociais: investigações em psicologia social. Petrópolis: Vozes, 2007.

MOSCOVICl, Serge. Pourquoi l'étude des représentations sociales em psychologie? Psychologie et Société, n.4, p. 7-24, 2002. 
OPIECHON, S. S.; ARAÚJO, R. C. Representações sociais sobre a criatividade musical das crianças. In: SIMPÓSIO DE COGNIÇÃO E ARTES MUSICAIS, 13., 2017, Curitiba. Anais [...]. Curitiba: UFPR, 2017. V. 1. p. 1-7.

PSCHEIDT, J.; ARAÚJO, R. C. Interação reflexiva e criatividade: uma experiência com alunos iniciantes em bateria. In: SIMPÓSIO DE COGNIÇÃO E ARTES MUSICAIS, 13., 2017, Curitiba. Anais [...]. Curitiba: UFPR, 2017. p. 1-7.

RAMOS, C. E. A. S. A música da Folia do Divino e a Festa do Divino no município de Guaratuba, Estado do Paraná: um estudo de caso sob a perspectiva da teoria das Representações Sociais. 334 f. Dissertação (Mestrado) - Universidade Federal do Paraná, Curitiba, 2019.

RAUSKI, R. D. Representações sociais sobre Música: estilos musicais e aula de música: uma problematização necessária. 168 f. Dissertação (Mestrado) - Universidade Estadual de Ponta Grossa, Ponta Grossa, 2015.

RAUSKI, R.; ROSSO, A. Representações sociais da aula de música no nono ano do ensino fundamental: fruição e aprendizagem. Revista Eletrônica de Ciência Administrativa, v. 17, n. 2, p. 335-352, 2017.

SOARES, G. D. B. A orquestra vai à escola: os significados de um concerto didático para alunos da educação básica. 217 f. Tese (Doutorado) - Universidade Federal do Rio de Janeiro, Rio de Janeiro, 2015. 